\title{
CURSO NORMAL: a formação de professores em nível médio, no Paraná (1996-2006)
}

\section{Teaching education: course at secondary school level in Paraná (1996-2006)}

\section{Angela Galizzi Vieira Gomide ${ }^{\mathrm{a}}$, Maria Elisabeth Blanck Miguel ${ }^{\mathrm{b}}$}

a Doutoranda do Programa de Pós-Graduação em Educação da Pontifícia Universidade Católica do Paraná (PUCPR), Professora da Universidade Estadual de Londrina (UEL), Londrina, PR -Brasil, e-mail: angelagomide@uel.br

b Doutora em História e Filosofia da Educação pela Pontifícia Universidade Católica de São Paulo (PUC-SP), Professora do Programa de Pós-Graduação em Educação da Pontifícia Universidade Católica do Paraná (PUCPR), Curitiba, PR - Brasil, email: maria.elisabeth@pucpr.br

\section{Resumo}

Este trabalho analisa as políticas educacionais para Formação de Professores para a Educação Infantil e Séries Iniciais do Ensino Fundamental, inserido na organização do sistema educacional brasileiro em nível médio, modalidade normal. Parte da compreensão do processo de reestruturação produtiva, das mudanças no mundo do trabalho e da reconfiguração do papel do estado interligados à educação, para apreender, neste contexto, as políticas para formação de professores em nível médio desenvolvidas no Estado do Paraná, entre 1996 e 2006. Analisa as orientações advindas da LBD 9394/

Rev. Diálogo Educ., Curitiba, v. 9, n. 27, p. 297-314, maio/ago. 2009 
96 e de documentos da Unesco, como a Declaração de Jomtien (1990) e Dakar (2000), consoantes com este projeto. Trata-se de uma pesquisa bibliográfica e documental, na qual, por meio de análise de conteúdo de documentos, estabelece um diálogo crítico com base nas obras de Tanuri (2000), Miguel (2007), Saviani (2005) e Harvey (1993). Os resultados indicam que, no decorrer da história, entre políticas para permanência ou extinção do referido curso, essa modalidade de ensino resiste às pressões e, no Paraná, embora construído com base epistemológica materialista histórica, explicita orientações internacionais da Unesco e cumpre um papel dualista na formação de professores e na consolidação da educação brasileira.

Palavras-chave: Educação. Legislação. Formação de professores. Unesco.

\section{Abstract}

This work analyzes educational policies for the Teachers' education concerning Children Education and Elementary School Early Grades, inserted in the organization of the Brazilian educational system at secondary school level. It is based on the understanding of the productive restructuration process, of the change in the world of work as well as of the state role reconfiguration interconnected to education, in order to apprehend, in this context, the policies for the teachers education at secondary school level developed in the State of Paraná, between 1996 and 2006. It analyzes the orientations from LDB (Brazilian Education Guidelines) $9394 / 96$ and from Unesco documents, such as Jomtien Declaration (1990) and Dakar (2000), in accordance with this project. It is a bibliographical and documentary research, in which, by means of the content analysis of documents, a critical dialogue is established based on works by Tanuri (2000), Miguel (2007), Saviani (2005) and Harvey (1993). The results show that, in the course of history, between policies for the permanence or extinction of the referred course, this teaching modality resists to pressures and, in Paraná, although built up on a historical materialist epistemological basis, it makes explicit Unesco's international orientations and accomplishes a dual role in the teachers education as well as in the consolidation of Brazilian education.

Keywords: Education. Legislation. Teachers' education. Unesco. 


\section{INTRODUÇÃO}

Este trabalho procura analisar a formação de professores para a Educação Infantil e Séries Iniciais do Ensino Fundamental em nível médio, na modalidade normal, inserida na Educação Básica do sistema educacional brasileiro.

O texto foi produzido com base em um estudo sobre a LBD 9.394/ 96, documentos dos organismos internacionais e da Secretaria Estadual de Educação (SEED-PR). Cientes de que as ideias aqui apresentadas revelam uma dimensão da nossa consciência histórica, questionamos: Qual o contexto sóciohistórico no qual está inserido o curso de formação de docentes em nível médio, na modalidade normal, no Estado do Paraná, no período de 1996 a 2006? Quais pressupostos legais, em âmbito nacional e estadual, dão sustentação ao desenvolvimento deste curso? Quais os fundamentos políticos e pedagógicos da Educação Profissional no Paraná? Quais os pressupostos teórico-filosóficos do atual currículo do curso de formação de professores, na modalidade normal? Qual a interferência dos organismos internacionais na formação de professores em nível médio no Paraná? Qual o papel social desempenhado pelo curso normal no Paraná na última década?

\section{O curso normal no contexto das políticas internacionais e nacionais}

No contexto mundial e nacional de 1996 até os dias atuais constatamos o fortalecimento da economia capitalista, com adoção de medidas de cunho neoliberal cujas diretrizes econômicas têm garantido uma ordem social regulada pelos princípios do livre mercado, no qual o papel do Estado é minimizado. Tendo o trabalho como fonte de renda e acumulação de capital, observamos a inculcação ideológica de valores, princípios e diretrizes de caráter economicista, em virtude do qual o lucro se sobrepõe, às custas do crescimento da desigualdade e da exclusão social.

A partir de 1990 com a globalização e a mundialização do capital invadindo o Brasil, verificamos uma nova configuração societária com manifestações reconhecidas pela terceirização, informatização, implementação de programas de qualidade total, recessão, desemprego estrutural e diminuição do papel do Estado. A reestruturação produtiva dos setores da economia, pela adoção de novas tecnologias e ajustes financeiros para dinamizar o sistema capitalista, condicionou a nossa sociedade a vivenciar profundas modificações na economia. A inserção competitiva nos mercados globalizados, a desregulamentação trabalhista e o subemprego são sinais visíveis da mudança de rumo em âmbito nacional e estadual. Harvey (1992,

Rev. Diálogo Educ., Curitiba, v. 9, n. 27, p. 297-314, maio/ago. 2009 
p. 140) denomina este processo de acumulação flexível do capital, que se apoia na flexibilidade dos processos de trabalho, dos mercados de trabalho, dos produtos e dos padrões de consumo e inaugura um novo modo de acumulação. Estas novas condições impostas pela inserção do país na modernidade trouxeram a reboque, custos sociais para grande parcela da população brasileira.

Direcionando nosso olhar para o Estado do Paraná, verificamos um processo contraditório de transformação. Considerado polo produtor e exportador agrícola, principalmente da soja e do trigo, o Paraná é destaque na pesquisa agrícola, na área de organismos geneticamente modificados. Por outro lado, evidencia contrastes sociais e um movimento de revisão e transformação dos valores tradicionais, impulsionado pelo choque de modernidade e de globalização. A entrada de grandes empresas estrangeiras do setor automobilístico e o fortalecimento da agroindústria contribuiu para consolidar o parque industrial próximo à região metropolitana de Curitiba e para construir uma nova identidade, reconhecida em nível nacional e não apenas regional, o que pode ser notado hoje, por exemplo, nas negociações e operações com o MERCOSUL. Apresenta também forte crescimento urbano, concentrado em cidades como Londrina, Maringá, Ponta Grossa, Cascavel e Guarapuava, influenciando positivamente o setor de vendas, compras e prestação de serviços. Há que se considerar também o foco turístico graças a eventos científicos e culturais, festas populares e paisagens culturais, como é o caso de Foz do Iguaçu. Contrapondo-se aos índices econômicos estatísticos superiores à média nacional, crescem também os problemas sociais provocados pela reestruturação produtiva da economia, os quais se fazem notar pela desestabilização dos trabalhadores estáveis, pela precariedade e flexibilização do trabalho e pela terceirização de mão-de-obra. Reconhecemos também a incorporação natural dos valores individualistas, competitivos e consumistas, difundidos pela sociedade capitalista, os quais contribuem para a desagregação social.

Alardeado pela imprensa interestadual de ser um Estado de 'primeiro mundo', demonstra em dados, de acordo com o IBGE (Tabelas comparativas da década de 1995 - 2005, 2006) que, em 2005, 6,6\% da população encontrava-se sem remuneração alguma, 34,8\% tinha emprego com carteira assinada e 14,3\%, sem carteira. Em 1995, os dados informam que 13,6\% não tinham remuneração, que 28,8\% dos trabalhadores estavam registrados com carteira assinada e 15,6\%, sem carteira.

No tocante à educação, a orientação política dos primeiros anos desse período sustentou um discurso de crise e fracasso da escola pública, fortalecendo, em consequência disso, o ensino privado. A escola vista pela perspectiva mercantilista teve seu papel vinculado à preparação da força de trabalho com uma formação geral, na qual predominou o raciocínio estratégico, a capacidade de trabalho cooperativo, bem como a disseminação de valores de individualidade, competitividade e empregabilidade.

Rev. Diálogo Educ., Curitiba, v. 9, n. 27, p. 297-314, maio/ago. 2009 
Tomando por base os dados estatísticos divulgados pelo IBGE (Tabelas comparativas da década de 1995 - 2005, 2006), esclarecemos que, nesta década, a taxa de analfabetismo entre a população de 15 anos diminuiu de 11,6\% para $7,1 \%$. Por outro lado, verificamos crescer o analfabetismo funcional, que em 1995 registrava um índice de 21,5\% e, em 2005, registrou 32,7\%. A melhoria nestes índices demonstra claramente a adoção de políticas de caráter economicista, em detrimento e ações de qualidade social, conforme esclareceremos no decorrer deste trabalho.

Quanto ao aspecto político-administrativo, no período histórico estabelecido por este trabalho, o Paraná teve dois governantes: Jaime Lerner e Roberto Requião. Aquele, representante do PFL, ocupou o governo do estado no período de 1995 a 2002, por duas gestões consecutivas. Este assumiu o governo do estado a partir de 2003, e cumprirá o seu mandato até 2010, visto ter sido reeleito nas eleições estaduais de 2006. Cumpre-nos informar, porém, que este é o seu terceiro mandato, porquanto havia governado o estado de 1991 a 1994.

Estes dois governos definiram diferentes estratégias políticas, orientadas por distintas concepções de Estado, sociedade e educação, que resultaram no estabelecimento de políticas públicas também diferenciadas.

Durante a gestão Lerner (1995-2002), o Paraná, mediante a reforma do estado e da educação, seguiu as orientações do Banco Mundial e adotou o discurso da gestão compartilhada e da busca da excelência na escola, programas evidenciados na educação para a empregabilidade. Implantou o modelo de administração empresarial, cuja concepção de educação focou o aprimoramento do indivíduo e da sociedade. Segundo Silva (2001, p. 156), a ênfase deslocou-se de uma formação de cunho democrático para uma formação de caráter competitivo, no contexto de um mercado de trabalho cada vez mais excludente e seletivo. Currículo por competência, gestão compartilhada da escola, princípios de qualidade total, ênfase nos resultados estatísticos, programas de aceleração da aprendizagem e correção de fluxo, inadequação e insuficiência dos materiais didáticos e a redução do tempo escolar, foram ações implantadas. Para Sapelli (2002, p. 196), de forma deliberada, subordinando-se aos interesses dos organismos internacionais, essas ações contribuíram para a precarizar a escola pública e enfraquecer qualitativamente o sistema estadual de ensino no Paraná.

No tocante ao Ensino Médio Profissional, presenciamos uma mudança radical nos rumos dos cursos técnicos. Pela adesão ao PROEM (Programa de Melhoria e Expansão do Ensino Médio), em outubro de 1996, a SEED-PR ordenou o fechamento dos cursos técnicos profissionalizantes na rede pública, para as escolas que aderiram a este programa. Entre eles, encontrava-se o Magistério. Com esta medida compulsória, os 1.080 cursos técnicos profissionalizantes da rede pública paranaense foram paulatinamente sendo encerrados, de modo que,

Rev. Diálogo Educ., Curitiba, v. 9, n. 27, p. 297-314, maio/ago. 2009 
no ano de 1997, as escolas que aderiram ao PROEM foram impedidas de matricular alunos para os primeiros anos dos cursos técnicos e até o ano 2000, as últimas turmas foram extintas, findando, portanto, a oferta do ensino médio profissionalizante na rede pública estadual.

Esta medida, de caráter privatizante, trouxe sérios prejuízos sociais aos jovens paranaenses, que se viram obrigados a procurar a iniciativa privada para efetivar a sua formação. Aos professores do curso coube o remanejamento para funções técnicas ou administrativas, o pedido de licenças especiais e, em muitos casos, a antecipação do fim da carreira profissional, com a aposentadoria ou exoneração. O acervo bibliográfico e os laboratórios das escolas foram desativados e doados para outros espaços educativos, gerando ociosidade e transformando prédios públicos em verdadeiros "elefantes brancos". Os oito anos sem ensino médio profissional na rede pública paranaense contribuíram para a criação de um vácuo na formação técnica no estado.

É importante destacar que a adoção desta medida no Estado do Paraná aconteceu antes mesmo das aprovações da LDB 9.394, em dezembro de 1996, e do decreto $\mathrm{n}^{\circ} 2.208$, em abril de 1997, que adequou o ensino técnico às novas formas do capital globalizado e de produção flexível, objetivando formar um trabalhador cidadão produtivo, adaptado e adestrado. Com a extinção do Curso Normal, a população interessada foi encaminhada para os estudos de nível pós-médio, com um ano de duração, ou para o curso Normal Superior, oferecido nas universidades privadas legalmente respaldadas pela LDB 9.394/96.

As medidas políticas adotadas na gestão Lerner, prioritariamente a extinção dos cursos técnicos, provocaram uma reação anti-hegemônica, configurada num movimento de resistência e de lutas por parte dos professores das escolas técnicas agrícolas e do magistério paranaenses, quando quatorze instituições não aceitaram as deliberações do governo do estado e se negaram a fechar seus cursos profissionalizantes. Deram continuidade aos trabalhos de formação técnica em nível médio, à revelia das determinações superiores, enfrentando escassez de recursos financeiros e humanos e de materiais pedagógicos. Essas quatorze escolas viram-se obrigadas a buscar apoio em seu próprio espaço de atuação. Segundo a SEED, os professores "enfrentaram um aparato discursivo e persuasivo muito forte de defesa das reformas como mudanças boas e modernas, além de sofrerem ameaças de não serem mais financiadas e modernizadas" (SEED, 2006a, p. 22). Por outro lado, ganharam credibilidade e respeito pelo movimento de luta desencadeado em defesa da formação profissional de professores de nível médio.

As primeiras iniciativas para reversão desta situação que durou oito anos, se deu em 2003, logo após a posse do governador Roberto Requião, que reabriu o debate sobre a formação de professores em nível médio no Paraná. A SEED organizou um conjunto de reuniões com a comunidade paranaense, visando

Rev. Diálogo Educ., Curitiba, v. 9, n. 27, p. 297-314, maio/ago. 2009 
definir um novo projeto para o ensino técnico e a formação de professores em nível médio. A presença de representantes das quatorze escolas resistentes, bem como os direcionamentos políticos dos organismos internacionais da época, foram fundamentais para definir os rumos dessa modalidade de ensino no Estado do Paraná. A atuação dos professores das universidades públicas paranaenses, respaldados nas orientações da ANFOPE (Associação Nacional pela Formação de Profissionais da Educação), e empenhadas em que a formação dos professores fosse realizada em nível superior, não foi suficiente para impedir o retorno do curso de formação de docentes para o nível médio, na modalidade normal.

$\mathrm{Na}$ verdade, apesar da intenção de formar o professor em nível superior datar de 1962, pelo Parecer 251/62, é apenas em 1996 que ela se expressa legalmente. Conforme esclarece o art 62, a formação de docentes para atuar na Educação Básica:

Far-se-á em nível superior, em curso de licenciatura de graduação plena em universidades e institutos superiores de educação, admitida como formação mínima para o exercício do magistério e na educação infantil e nas quatro séries do ensino fundamental, a oferecida em nível médio, na modalidade normal (LDB 9.394/96, art 62).

Este artigo mostra um caráter dúbio na formação do professor da educação básica (educação infantil, ensino fundamental e ensino médio) em nível superior, ao passo que admite a modalidade normal, em nível médio, para o professor da educação infantil e séries iniciais, revelando uma dimensão no mínimo instigante: Descompromisso? Desqualificação? Simplificação? Aligeiramento?

A posição da APP Sindicato (Associação dos Professores do Paraná), das demais Secretarias do Estado do Paraná corroboraram com essa decisão. As orientações da Unesco, ao definirem as políticas educacionais para os países em desenvolvimento, haja vista sua preocupação com a educação, a situação da mulher e das crianças dos países em desenvolvimento, também influenciaram, conforme elucidaremos a seguir.

Em 1945, no momento pós-guerra, foi fundada, como órgão da ONU, a Unesco (Organização das Nações Unidas Para a Ciência, a Cultura e a Educção), com o objetivo de reduzir o analfabetismo e contribuir para a construção de um mundo de paz e segurança, mediante a educação, a ciência, a cultura e as comunicações. Por ser uma agência atuante no âmbito social/ideológico, seus princípios norteiam a educação brasileira desde então e convencem os dirigentes a adotar suas sugestões. Isto porque, para a Unesco, a educação é considerada como um dos pilares de sustentação da sociedade e é por meio dela que o governo consolida valores e crenças que ratificarão as mudanças em curso.

Rev. Diálogo Educ., Curitiba, v. 9, n. 27, p. 297-314, maio/ago. 2009 
Dentre os vários documentos lançados por estes organismos e que contribuíram para definir prioridades políticas e educativas no Brasil, podemos destacar o emitido pela Conferência Mundial de Educação para Todos, realizada em Jomtien, em 1990. Nessa ocasião, sensibilizada pelos dados alarmantes de analfabetismo e fracasso escolar, a Unesco sugeriu a concentração de esforços para satisfazer as necessidades básicas de aprendizagem (NEBAS), meta que deveria ter sido alcançada até o ano 2000.

Defendeu com isso, juntamente com o Banco Mundial, a centralidade na educação básica, a fim de que toda a população brasileira viesse a alcançar os "códigos da modernidade". Apesar de expressar ambivalência, esses códigos representam um "conjunto mínimo de conhecimentos e destrezas necessários para participar da vida pública e desenvolver-se produtivamente na sociedade moderna" (SHIROMA, 2000, p. 64). Como se pode verificar, sua dimensão é restrita à habilidade de saber ler, escrever e calcular.

A Declaração de Dakar (2000), por outro lado, estabeleceu o ano 2015 como prazo para o alcance das metas definidas na $1^{\text {a }}$ Conferência Mundial de Educação para Todos. As metas propostas nesta oportunidade ficaram assim definidas:

1 - Expansão e aprimoramento da assistência e educação da primeira infância, especialmente para as crianças mais vulneráveis e desfavorecidas.

2 - Garantir que em 2015 todas as crianças, especialmente as crianças em situações difíceis e crianças pertencentes à minoria étnicas, tenham acesso a uma educação primária de boa qualidade, gratuita e obrigatória, e possibilidade de completá-la.

3 - Assegurar as necessidades básicas de aprendizagem de todos os jovens e adultos sejam satisfeitas mediante o acesso eqüitativo à aprendizagem apropriada e a programas de capacitação para a vida.

4 - Atingir, em 2015, 50\% de melhora nos níveis de alfabetização de adultos, especialmente para as mulheres, e igualdade de acesso à educação fundamental e permanente para todos os adultos

5 - Eliminar, até 2005, as disparidades existentes entre os gêneros na educação primária e secundária e até 2015 atingir a igualdade entre os gêneros em educação, concentrando esforços para garantir que as meninas tenham pleno acesso, em igualdade de condições, à educação fundamental de boa qualidade e que consigam completá-la.

Rev. Diálogo Educ., Curitiba, v. 9, n. 27, p. 297-314, maio/ago. 2009 
6 - Melhorar todos os aspectos da qualidade da educação e assegurar a excelência de todos, de modo que resultados de aprendizagem reconhecidos e mensuráveis sejam alcançados por todos, especialmente em alfabetização, cálculo e habilidades essenciais para a vida (Unesco, 2000, p. 18, grifo nosso).

Considerando a importância dada pela Unesco às questões da mulher, das crianças em condições de risco, da alfabetização, do ensino primário, da educação de jovens e adultos e das habilidades essenciais para a vida, conforme grifamos acima; considerando ser a educação um direito humano essencial para o desenvolvimento sustentável, para assegurar a paz e a estabilidade, indagamos: Qual modelo de educação é defendido pela Unesco? Que concepção de professor deverá permear as políticas públicas para formação docente no Brasil? Que pressupostos teóricos devem sustentar uma proposta de formação de professores? Como atender a demanda por professores qualificados? $\mathrm{E}$, finalmente, como estas questões se materializam nas políticas para a formação de professores no Estado do Paraná1?

Ao nos referimos à interferência da Unesco nas definições políticas para a educação e a formação de professores no Brasil, principalmente pela prioridade dada à educação básica, esclarecemos que a concepção adotada pela Unesco contradiz a da legislação brasileira atual. De um lado, conforme expressa o art 21 da LDB 9.394/96, a Educação Básica é definida como primeiro nível de educação e compreende a educação infantil, ensino fundamental e ensino médio, etapas que envolvem um conjunto de conhecimentos considerados básicos e essenciais ao ser humano, mas que não se restringem apenas ao ensino fundamental, como defende a Unesco. Por outro lado, o Estado brasileiro revela seu caráter minimalista, ao garantir como obrigatório e gratuito apenas o ensino fundamental (Art 4 , LDB 9.394/96).

Outro momento histórico nas políticas educacionais do Paraná, consolidado na gestão Roberto Requião (2003 até os dias atuais), expressa uma nova concepção para educação, ensino profissionalizante e formação de professores. O concurso público para professores e pedagogos e a retomada dos cursos técnicos da rede pública, por exemplo, figuram entre as ações políticas imediatamente implementadas.

Em nossos estudos, verificamos que a política pública para a educação profissional implantada pela SEED-PR, por meio do Departamento de Educação Profissional, foi decisiva para a retomada da oferta da educação profissional. Contribuíram também para a consolidação desta formação, a revogação do Decreto 2.208/97 e a promulgação do Decreto 5.154/2004, o qual deu sustentação legal para que se pudesse "ofertar esta modalidade de ensino,

1 Estas questões serão respondidas no decorrer da pesquisa.

Rev. Diálogo Educ., Curitiba, v. 9, n. 27, p. 297-314, maio/ago. 2009 
expandi-lo de acordo com as necessidades e tendências socioeconômicas das regiões do estado e ainda reestruturar o currículo do curso, de modo a favorecer a formação do cidadão / aluno / trabalhador" (SEED, 2006b, p. 18).

Com base no estudo do documento "Diretrizes da Educação Profissional: fundamentos políticos e pedagógicos" da SEED,

esta nova legislação possibilitou conceber propostas curriculares considerando a necessária articulação entre as diferentes dimensões do trabalho de formação profissional do cidadão / aluno, na perspectiva da oferta pública da Educação Profissional técnica de nível médio, enfatizando o trabalho, a cultura, a ciência e a tecnologia, como princípio fundantes da organização curricular integrada ao Ensino Médio (SEED, 2006b, p. 18).

Ainda de acordo com este documento, para a retomada da oferta da educação profissional foram definidos os seguintes direcionamentos:

- $\quad$ expansão e reestruturação curricular;

- $\quad$ instituição de quadro próprio de professores para essa modalidade;

- $\quad$ formação continuada do seu quadro docente e técnico;

- melhoria da estrutura física e material dos estabelecimentos e

- $\quad$ sua manutenção sem a cobrança de taxas de qualquer natureza. (SEED, 2006b, p. 18).

Diante da possibilidade de reimplantar uma política pública para a educação profissional e formação de professores em nível médio, na modalidade normal e, levada pela necessidade de construir um projeto político pedagógico anti-hegemônico que abarcasse a defesa de uma escola pública, gratuita e de qualidade social em todos os níveis e modalidades, e enfrentasse o novo modelo de acumulação flexível, a SEED-PR elaborou a sua "Proposta pedagógica curricular do curso de formação de docentes da educação infantil e anos iniciais do ensino fundamental, em nível médio, na modalidade normal" (SEED, 2006a).

$\mathrm{Na}$ organização curricular e na implantação gradativa ${ }^{2}$ do curso a partir de 2004, a SEED-PR adotou, de forma pioneira, a concepção curricular integrada entre educação profissional e o ensino médio. A SEED (2006b, p. 20)

2 Em 2003 existiam 14 escolas. Com a política de expansão gradativa, em 2004 foram implantadas mais 31 escolas; em 2005, mais 41e em 2006 mais 27 escolas com o curso normal, totalizando 113 instituições.

Rev. Diálogo Educ., Curitiba, v. 9, n. 27, p. 297-314, maio/ago. 2009 
entende que essa concepção rompe com a dimensão que articula diretamente a formação profissional ao mercado de trabalho e à empregabilidade e laboralidade. Em razão disso assume o compromisso com a formação humana dos alunos, facultando-lhes a apreensão dos conhecimentos científicos, tecnológicos e históricosociais pela via escolarizada.

Com essa postura, a SEED-PR enfrentou uma questão nodal dos cursos técnicos: a dualidade estrutural. Frigotto (1989a) referiu-se ao acerto dessa postura quando defendeu que a escola técnica foi extremamente produtiva ao abandonar a formação geral, ou seja, a formação politécnica em nível médio, que fragmentava os conteúdos, trabalhava de forma estanque, contribuía para a alienação do trabalhador e reforçava o caráter dualista da educação brasileira. Por isto, o autor defende "a organização da Educação Básica unitária, politécnica e, portanto, não dualista, que articule cultura, conhecimento, tecnologia e trabalho como direito de todos e condição de cidadania e da democracia efetivas" (FRIGOTTO, 1989b, p. 10). Nesse horizonte, a expectativa social mais ampla é poder avançar na direção da Educação Básica, não dualista, conforme defende o autor. Não se trata de uma "relação linear com o mercado de trabalho, mas mediada, sem o que não se cumpre os dois imperativos: de justiça social e de acompanhamento das transformações técnico-científicas do mundo do trabalho", conforme alerta Frigotto (1989b, p. 11).

No caso do curso de formação de professores, na modalidade normal, esta integração ${ }^{3}$ foi definida como o diferencial da grade curricular do curso, e está ocorrendo por meio da articulação entre os conhecimentos gerais e os específicos do curso em nível médio. Em nossa opinião, este é o desafio: formar tecnicamente os professores e supri-los de conhecimentos básicos e essenciais capazes de consolidar a sua formação inicial, o que implica em superar os limites do magistério da década de 70, que priorizava o saber fazer, ou seja, o pragmatismo, em detrimento do conhecimento humano, omnilateral, unitário. Implica também em amenizar as dicotomias e fragmentações materializadas pela escola capitalista, como o divórcio entre o saber teórico e a práxis, o pensar e o fazer, o conteúdo e a forma.

Com o objetivo de "formar docentes para atuarem na Educação Infantil e nas quatro séries do Ensino Fundamental assegurando-lhes a formação básica nacional comum de qualidade e também as competências e habilidades inerentes à função docente" (Deliberação CEE 010/99, art 2º, a proposta pedagógica do curso normal

Esta definição apóia-se no art 10 da Deliberação CEE nº10/99, que regulamenta o curso normal em âmbito estadual desde o ano de 1999 e no Decreto 5.154/2004.

Rev. Diálogo Educ., Curitiba, v. 9, n. 27, p. 297-314, maio/ago. 2009 
Deverá garantir o domínio dos conteúdos curriculares necessários à constituição de competências gerais e específicas, de forma articulada e contextualizada, de caráter interdisciplinar, compondo-se das seguintes áreas ou núcleos curriculares: formação básica para o ensino médio e formação específica assegurando a capacitação profissional (DELIBERAÇÃO CEE 010/99, Art 10).

Para que este objetivo seja alcançado, o curso normal foi organizado com duração de 4800 horas, distribuídos em 4 anos. De acordo com matriz curricular que vigorou entre 2004-2006 ${ }^{4}$ (SEED, 2006a), o curso ficou assim organizado:

a) Base Nacional Comum: Língua Portuguesa e Literatura; Língua Estrangeira Moderna; Arte; Educação Física; Matemática; Física; Química; Biologia; História e Geografia.

b) Fundamentos da Educação: Fundamentos Históricos da Educação; Fundamentos Filosóficos da Educação; Fundamentos Sociológicos da Educação; Fundamentos Psicológicos da Educação; Fundamentos Históricos e Políticos da Educação Infantil; Concepções Norteadoras da Educação Especial;

c) Gestão escolar: Trabalho Pedagógico na Educação Infantil e Organização do Trabalho Pedagógico.

d) Metodologias: Literatura Infantil; Metodologia do Ensino de Português / Alfabetização; Metodologia do Ensino de Matemática; Metodologia do Ensino de História; Metodologia do Ensino de Geografia; Metodologia do Ensino de Ciências; Metodologia do Ensino de Arte e Metodologia do Ensino de Educação Física.

e) Prática de formação: Estágio Supervisionado

4 Para elucidar o leitor, comunicamos que a partir de 2007 a matriz curricular do curso normal manteve a duração, a carga horária do curso e alterou a organização/integração das disciplinas nos eixos articuladores ficando assim definidos: Base Nacional Comum (Língua Portuguesa e Literatura; Arte; Educação Física; Matemática; Física; Química; Biologia; História, Geografia); Parte Diversificada (Língua Estrangeira Moderna) e a Formação Específica (Fundamentos Históricos da Educação; Fundamentos Filosóficos da Educação; Fundamentos Sociológicos da Educação; Fundamentos Psicológicos da Educação; Fundamentos Históricos e Políticos da Educação Infantil; Concepções Norteadoras da Educação Especial; Trabalho Pedagógico na Educação Infantil e Organização do Trabalho Pedagógico; Literatura Infantil; Metodologia do Ensino de Português/ Alfabetização; Metodologia do Ensino de Matemática; Metodologia do Ensino de História; Metodologia do Ensino de Geografia; Metodologia do Ensino de Ciências; Metodologia do Ensino de Arte e Metodologia do Ensino de Educação Física; Prática de formação) (SEED-PR, 2006a).

Rev. Diálogo Educ., Curitiba, v. 9, n. 27, p. 297-314, maio/ago. 2009 
No estudo que fizemos sobre esta proposta reconhecemos uma orientação pedagógica emancipadora, em razão de seu vínculo com pressupostos teórico-metodológicos respaldados na concepção materialista histórica dialética, que pretende explicar a história das sociedades, a partir da existência material dos homens, nas relações sociais de produção, essencialmente econômicas e técnicas. Enriquece a proposta a definição de princípios pedagógicos que devem direcionar o processo de formação inicial dos professores na atualidade, no Estado do Paraná. São eles: o trabalho como princípio educativo, a práxis como princípio curricular e o direito da criança ao atendimento escolar.

Para a SEED (2006a, p. 23):

Tomar o trabalho como princípio educativo implica compreender a natureza da relação que os homens estabelecem com o meio natural e social, bem como as relações sociais em suas tessituras institucionais, as quais desenham o que chamamos de sociedade. Assim, a educação é também uma manifestação histórica do estar e do fazer humano que fundamentam o processo de socialização humana.

Significa compreender o trabalho para além de tarefas e ofícios laborais, realizado de forma alienante e trocado por proventos financeiros. Significa ainda compreendê-lo na dimensão ontocriativa, como atividade essencial e vital ao ser humano, que lhe faculta a realização em sua dimensão humana plena. Nesse contexto, a educação é um trabalho visto que realiza como "ato de produzir, em cada indivíduo singular, a humanidade que é produzida histórica e coletivamente pelo conjunto dos homens" (SAVIANI, 1994, p. 24). Concordamos com esta posição, pois acreditamos ser a educação uma dimensão essencial para alcançarmos o objetivo pleno da emancipação humana.

A práxis como princípio curricular nos leva a compreender a dimensão teórico-prática na qual este curso está fundado. Além da dimensão integradora entre a base nacional comum e a parte diversificada, a grade curricular do curso de formação de professores destinou 800 horas para as atividades relacionadas à prática de formação, que deverá ocorrer desde o $1^{\circ}$ ano do curso. O empenho da SEED é para que o estágio supervisionado se constitua como elemento articulador da relação entre teoria e prática, unidade indissolúvel entre as duas dimensões distintas e necessárias à formação inicial do professores. Com esta unidade, pretende-se formar o professor e ao mesmo tempo, inseri-lo num processo permanente de reflexão sobre o fazer pedagógico em suas múltiplas relações, desde o que ensinar, como ensinar, o para que ensinar e o para quem ensinar. Esta postura materialista-histórica e dialética instiga as pessoas responsáveis pela concretização dessa proposta, seja

Rev. Diálogo Educ., Curitiba, v. 9, n. 27, p. 297-314, maio/ago. 2009 
no espaço diretivo dos núcleos regionais ou Secretaria Estadual de Educação, seja no espaço escolar, como docentes do curso, a utilizarem os espaços de contradição, para alavancar um processo de transformação social.

Por outro lado, o princípio do "direito da criança ao atendimento escolar" direciona as ações estabelecidas pela SEED na definição do papel social do curso normal e, por conseguinte, na política para com a formação de professores em nível médio no Paraná, com foco prioritário na educação infantil, com respaldo nos seguintes princípios:

- $\quad$ respeito à dignidade e aos direitos da criança, consideradas nas suas diferenças individuais, sociais, econômicas, culturais, étnicas, religiosas, etc;

- direito das crianças de brincar, como forma particular de expressão, pensamento, interação e comunicação infantil;

- acesso das crianças aos bens socioculturais disponíveis, ampliando o desenvolvimento das capacidades relativas à expressão, à comunicação, à interação social, ao pensamento, à ética, e à estética;

- $\quad$ socialização das crianças por meio de sua participação e inserção nas mais diversificadas práticas sociais, sem discriminação de espécie alguma;

- atendimento aos cuidados essenciais associados à sobrevivência e ao desenvolvimento de sua identidade. (SEED, 2006a, p. 26-27).

De acordo com estes princípios, a SEED explicita o papel social do curso normal desenvolvido sob sua responsabilidade com vistas à formação de professores para a educação infantil.

Reconhecemos a preocupação do estado ao reimplantar e definir, na atualidade, uma política pública para a formação de professores em nível médio. Por meio de uma proposta pedagógica inovadora, num modelo integrado, politécnico e unitário, o Paraná resgata e assume mais uma vez, o curso normal.

Muitas dificuldades foram e ainda estão sendo enfrentadas. As escolas resistentes, ou seja, aquelas que não encerraram o oferecimento do curso de formação de professores em nível médio, na modalidade normal, entre 1996 e 2003, desempenharam um papel fundamental. Consideradas escolas-modelo, abriram seus projetos políticos pedagógicos para a SEED-PR, socializaram ações educativas inovadoras e atuaram como "assessoras" daquelas que, aproveitando uma oportunidade política no estado e visando atender demanda por esta formação, reiniciaram o processo de reimplantação do curso normal em seus estabelecimentos de ensino.

Rev. Diálogo Educ., Curitiba, v. 9, n. 27, p. 297-314, maio/ago. 2009 
Para as demais, este recomeço, não foi sem dor. Ao contrário, tiveram de enfrentar: falta de professores para as disciplinas; bibliotecas desmanteladas; arquivos e documentos importantes inexistentes; desconhecimento da proposta pedagógica; dificuldade em compreender a concepção integrada; ausência de equipe pedagógica para coordenar o curso; ausência de campo de estágio, além de outras dificuldades. Enfrentaram também uma demanda reprimida do curso normal. No que concerne à modernização, à mundialização do capital e o avanço tecnológico, acreditamos nos professores, na escola e na educação como uma prática social concreta.

No que tange à formação de professores em nível superior, a recente aprovação das Diretrizes Curriculares Nacionais ${ }^{5}(\mathrm{DCN})$ para o curso de graduação em Pedagogia definiu este curso como licenciatura e logo, como espaço privilegiado, ainda que não exclusivo, da formação de professores para a educação infantil e anos iniciais do ensino Fundamental. E mais: sua destinação e abrangência

Aplicam-se à formação inicial para o exercício da docência na Educação Infantil e nos Anos Iniciais do Ensino Fundamental, nos cursos de Ensino Médio, na modalidade Normal, e em cursos de Educação Profissional na área de serviços e apoio escolar, bem como em outras áreas nas quais sejam previstos conhecimentos pedagógicos. (Art 2º Resolução CNE nº 1, de 15/05/2006).

Este artigo considera a docência na educação infantil, anos iniciais do ensino fundamental e no ensino médio, (na modalidade normal ou na educação profissional), como base para a formação do pedagogo. O pedagogo tem também seu campo de atuação na área de serviços, de apoio escolar e em todos os espaços onde se requeiram conhecimentos pedagógicos. Com isso, abre-se um amplo horizonte para a formação e atuação profissional dos pedagogos. Reconhecemos que a formação em nível superior ultrapassa qualitativa e tecnicamente à formação em nível médio. A formação superior certamente contribuirá para que os professores alcancem melhores oportunidades no mundo do trabalho, seja na esfera pública, seja na esfera privada.

Acreditamos também que a nova configuração do ensino fundamental de nove anos representa ganhos e perdas para o contexto educacional. Se, por um lado, representa a concretização de uma nova proposta pedagógica, planejada para nove anos, por outro lado, retira dos alunos de seis anos a educação infantil, o que pode fragilizar essa etapa de ensino na rede pública. $O$ fato dessa etapa constituir-se como Educação Básica (Art 21, LDB 9.394/96) não foi suficiente para sua inserção nas prioridades orçamentárias dos municípios paranaenses. Conforme demonstram as estatísticas (IBGE-Tabelas comparativas da década de 1995 - 2005, 2006), no ano

5 Resolução CNE, no 01 de 15 de maio de 2006.

Rev. Diálogo Educ., Curitiba, v. 9, n. 27, p. 297-314, maio/ago. 2009 
$2005,16,8 \%$ das crianças de 0 a 3 anos e $66,0 \%$ das de 4 a 6 anos receberam atendimento escolar. Isso demonstra que o espaço da educação infantil está deficitário e em sua maioria, preenchido por ações sociais filantrópicas, beneficentes e não governamentais. A retirada das crianças de seis anos desse conjunto alterará esses resultados.

\section{CONSIDERAÇÕES FINAIS}

Passados doze anos da aprovação da LDB 9.394/96, ainda temos muitos desafios a superar. No Paraná, a universalização do ensino fundamental em 2005, com índice de $97,5 \%$ de frequência dos alunos, não foi alcançada no ensino médio, cujo índice ficou em 78,4\%. Em 1995 os dados revelam o índice de 90,3\% de frequência dos alunos no ensino fundamental e 57,8 no ensino médio. Revelam também aumento no índice do analfabetismo funcional de $21,5 \%$ para $32,7 \%$, evidenciando que a melhoria quantitativa, não foi acompanhada da melhoria qualitativa.

Com relação ao curso normal, as discussões realizadas até o momento nos revelam um quadro de contradições. No decorrer da história ${ }^{6}$, essa modalidade de ensino resiste às pressões de uma política contraditória, ora a favor ora contra sua permanência.

No caso do Paraná, inserido num projeto em favor da Educação Profissional, o curso normal consolida-se como formação inicial de professores, fundamentado numa proposta inovadora, na qual se integram o curso médio regular e profissional, onde as dimensões trabalho, cultura, ciência e tecnologia se apresentam de forma indissociável e se materializam como uma política pública estadual. Nestas condições, o curso normal apresenta-se como uma possibilidade para o início da carreira profissional docente. Por conseguinte, chamamos a atenção para o interesse e motivação da Unesco pela formação do professor no curso normal, em razão de sua dimensão pragmática e do enfoque nas competências difundidas no mercado como novo perfil profissional da modernidade. A facilidade para acesso ao trabalho na educação infantil, proveniente da grande demanda, não poderá criar no imaginário das alunas, a ilusão de mobilidade social e profissional. Neste caminhar há necessidade de se realizar a profissionalização docente, o que deverá acontecer por meio de uma política pública de formação continuada de professores. Lembramos a todos os envolvidos com este curso, seu dever político de conscientizar as alunas sobre a necessidade de continuarem seus estudos, em nível de graduação, de forma presencial.

Em curto prazo, o curso normal configura-se como uma medida compensatória, para satisfazer as necessidades imediatas de formação de professores. Atende às determinações dos organismos internacionais e estabelece a dualidade na educação.

6 Sugerimos os trabalhos de MIGUEL, 1997, 2007, e TANURI, 2004, que discutem historicamente este percurso.

Rev. Diálogo Educ., Curitiba, v. 9, n. 27, p. 297-314, maio/ago. 2009 
Em longo prazo, respaldo nas categorias trabalho, cultura, ciência e tecnologia, como princípios fundantes da organização curricular integrada ao ensino médio, consolida um espaço anti-hegemônico de lutas e resistências visando superar as condições históricas do capitalismo e das políticas neoliberalizantes e consolidar a formação de professores e a educação emancipadora.

\section{REFERÊNCIAS}

BRASIL. Constituição da República Federativa do Brasil. São Paulo: Imprensa Oficial do Estado, 1988.

. Leis e Diretrizes e Bases da Educação Nacional. Lei 9.394/96, 20 dez. 1996. Estabelece as diretrizes e bases da educação nacional. Diário Oficial da União, Brasília, ano 134, n. 248, p. 27833-27841, dez. 1996

- Institui as Diretrizes Curriculares Nacionais para a Educação Profissional de Nível Técnico. Resolução CEB nº 2, de 19 de abril de 1999. Diário Oficial da União, Brasília, 22 dez. 1999. Seção 1, p. 229.

. Conselho Nacional de Educação. Decreto n. 5.154/04 de 23 de julho de 2004. Diário Oficial da União, Brasília, ano 134, n. 248, p. 27833-27841, 26 jul. 2004.

, Conselho Nacional de Educação. Resolução n. 01, de 15 de maio de 2006. Institui as Diretrizes Curriculares Nacionais para o curso de graduação em Pedagogia, licenciatura. Diário oficial da União, Brasília, 16 de maio de 2006, seção 1, p. 11. 2006.

FRIGOTTO, Gaudêncio. A produtividade da escola improdutiva: um reexame das relações entre educação e estrutura econômico-social capitalista. 3. ed. São Paulo: Cortez, 1989a.

. Concepções e mudanças no mundo do trabalho e o ensino médio. In: FRIGOTTO, Gaudêncio; CIAVATTA, Maria; RAMOS, Marise. Ensino médio integrado: concepção de contradição. São Paulo: Cortez, 1989b. p. 08-26.

HARVEY, David. Condição Pós-moderna: uma pesquisa sobre as origens da mudança cultural. São Paulo: Loyola, 1993.

HIDALGO, Angela Maria; SILVA, Ileizi. (Org.). Educação e sociedade: as mudanças nos sistemas de ensino do Brasil e do Paraná na década de 90. Londrina: Editora da UEL, 2001.

IBGE. Tabelas comparativas da década de 1995-2005-2006. Disponível em: <http://ibge.gov.br/estadosat/imprimir,php?sigla=pr\&tema+educacao2007>. Acesso em: 20 jul. 2008.

Rev. Diálogo Educ., Curitiba, v. 9, n. 27, p. 297-314, maio/ago. 2009 
MIGUEL, Maria Elisabeth Blanck Miguel. A escola normal no Paraná. Curitiba: 2007. Mimeografado.

A formação do professor e a organização social do trabalho. Curitiba: Editora da UFPR, 1997.

PARANÁ. Secretaria de Estado da Educação. Superintendência de Educação. Departamento de Educação Profissional. Proposta pedagógica curricular do curso de formação de docentes da educação infantil e anos iniciais do ensino fundamental. Curitiba: SEED-PR, 2006a.

. Secretaria de Estado da Educação. Superintendência de Educação. Departamento de Educação Profissional. Diretrizes da educação profissional: fundamentos políticos e pedagógicos. Curitiba: SEED-PR, 2006b.

. Conselho Estadual de Educação. Sistema Estadual de Ensino. Deliberação 010/99. 1999. Disponível em: <http://celepar7cta.pr.gov.br/seed/ deliberações.nsf>. Acesso em: 15 jul 2007.

SAPELLI, Marlene Lúcia Siebert. Políticas educacionais do governo Lerner no Paraná (1995-2002). Cascavel: Igol, 2003.

SAVIANI, Dermeval. História da formação docente no Brasil: três momentos decisivos. Revista do Centro de Educação, v. 30, n. 2, p. 11-26, 2005.

SHIROMA, Eneida Oto; MORAES, Maria Célia Marcondes; EVANGELISTA, Olinda. Política educacional. Rio de Janeiro: DP\&A, 2000.

TANURI, Maria Leonor. História da formação de professores. Revista Brasileira de Educação, maio/ago. n. 14, p. 61-88, 2000.

UNESCO. Educação para todos fazendo face aos nossos compromissos coletivos: Fórum Mundial de Dakar. Brasília: Unesco, 2000. Disponível em: $<$ www.unesco.org. br/publicações/livros/educatodosdakar/mostra_padrao>. Acesso em: 17 jan. 2006.

UNICEF. Declaração mundial sobre educação para todos e plano de ação para satisfazer as necessidades básicas de aprendizagem. Brasília: Unicef, 1991.

Recebido: 05/01/2009

Received: 01/05/2009

Aprovado: 15/03/2009

Approved: 03/15/2009

Revisado: 22/07/2009

Reviewed: 07/22/2009

Rev. Diálogo Educ., Curitiba, v. 9, n. 27, p. 297-314, maio/ago. 2009 